\title{
Primary Diffuse Large B-Cell Lymphoma of the
} Female Urethra: A Case Report and Review of the Literature

This article was published in the following Dove Press journal: OncoTargets and Therapy

\author{
Haiping Zeng' \\ Jun Wang ${ }^{2}$ \\ Runpei Deng ${ }^{3}$ \\ Zhiqiang Chen ${ }^{4}$
}

'The Second School of Clinical Medicine, Guangzhou University of Chinese Medicine, Guangzhou 5 I0405, People's Republic of China; ${ }^{2}$ Department of Urology, The First Affiliated Hospital of Guangzhou University of Chinese Medicine, Guangzhou 5 10405, People's Republic of China; ${ }^{3}$ The First School of Clinical Medicine, Guangzhou University of Chinese Medicine, Guangzhou 510405, People's Republic of China; ${ }^{4}$ Department of Surgery, Guangdong Provincial Hospital of Chinese Medicine, Guangzhou 5I0I20, People's Republic of China
Correspondence: Zhiqiang Chen Department of Surgery, Guangdong Provincial Hospital of Chinese Medicine, III Dade Road, Guangzhou 510120, People's

Republic of China

Tel +86 020-8I887233

Email profchen7233@I26.com

\begin{abstract}
Primary urethral non-Hodgkin's lymphoma (NHL) is uncommon. This case study reports the case of a 52-year-old woman with a light red mass at the urethral orifice. Her clinical manifestations included frequent urination, urgency, dysuria, and occasionally blood in urine. The tumor was surgically removed, and the pathological and immunohistochemistry examination confirmed the presence of a diffuse large B-cell lymphoma (DLBCL). Examination using positron emission tomography/computed tomography (PET/CT) revealed multiple hypermetabolic lymph nodes next to the external iliac vessels and bilateral inguinal regions, and focal hypermetabolic lesions in the vulvar nodules (consistent with the changes caused by lymphoma infiltration). Eight cycles of chemotherapy with rituximab, cyclophosphamide, doxorubicin, vincristine, and dexamethasone (R-CHOP) were prescribed after surgery. Re-examination using PET/CT showed lack of hypermetabolic tumor recurrence signs, and the presence of multiple slightly large lymph nodes in the lateral iliac vessels and inguinal regions, but without significant lymph node metabolism increases. To date, only fifteen cases of primary diffuse large B-cell lymphoma of the urethra (including this one) have been reported in the literature. Therefore, we reviewed the etiology, clinical manifestations, diagnosis, differential diagnosis, treatment, and prognosis of DLBCL based on the existing literature to help characterize this rare disease.
\end{abstract}

Keywords: urethral malignant tumor, non-Hodgkin's lymphoma, diffuse large B-cell lymphoma, R-CHOP chemotherapy

\section{Introduction}

Adult non-Hodgkin lymphoma (NHL) is a malignant proliferative disease originating from the lymphatic reticulum system and is prone to early distant spread. Diffuse large B-cell lymphoma (DLBCL) is the most common histological subtype, accounting for about one-third of cases. ${ }^{1}$ DLBCL occurs mainly in the lymphatic system, and the most common site is the gastrointestinal tract, followed by the skin, and central nervous system. ${ }^{2}$ Malignant lymphomas involving the urogenital tract are rare, and more than $90 \%$ of these are secondary to other primary disease. The most common site of primary urogenital NHL is the bladder. ${ }^{3}$ Primary ovarian NHLs account for only $0.5 \%$ of NHLs, ${ }^{4}$ and primary NHL in the female urethra is even scarcer. The morbidity and mortality of NHL are among the top ten caused by tumors worldwide. ${ }^{5}$ In addition, the 5-year survival rate of patients with DLBCL is lower than the average for patients with NHL. ${ }^{6,7}$ To date, only fifteen cases of primary diffuse large B-cell lymphoma of the urethra have been reported in the 
literature. However, the clinical course and the therapeutic management for this disease have been discussed only in eight reports.

\section{Case Report}

A 52-year-old woman was admitted to the First Affiliated Hospital of Guangzhou University of Chinese Medicine with the chief complaint of a one-year history of urinary frequency, urgency, and dysuria. Physical examination revealed absence of swelling of superficial lymph nodes, and normal perineal skin coloration, without swelling or induration. A light red mass approximately $1.0 \times 0.8 \mathrm{~cm}$ in size was seen at the 6 o'clock position on the urethral orifice. The tumor protruded outside of the urethra with mild tenderness and no bleeding. Laboratory results showed that the ratio of albumin to globulin was 1.7 , and that the complete blood counts, neutrophil counts, lactate dehydrogenase and cancer antigen levels, renal and liver function tests were normal. Both hepatitis B virus markers and human immunodeficiency virus antibody tests were negative.

A surgical resection was performed considering the mass as a urethral polyp. During the operation, the swollen material was hard, and lacked obvious bleeding. It was completely freed from surrounding tissues and was removed for pathological examination. The pathological results revealed the proliferation of large lymphocytes (Figure 1). Immunohistochemical markers present included heteromorphic large lymphocytes CD20 $(+++)$, CD79a $(+++)$, CD3(-), BCL-2(-), BCL-6(+), CD10(-), MUM-1(+), Ki-67(+>90\%), and CD30 scattered positive (Figure 2). These features suggested the presence of

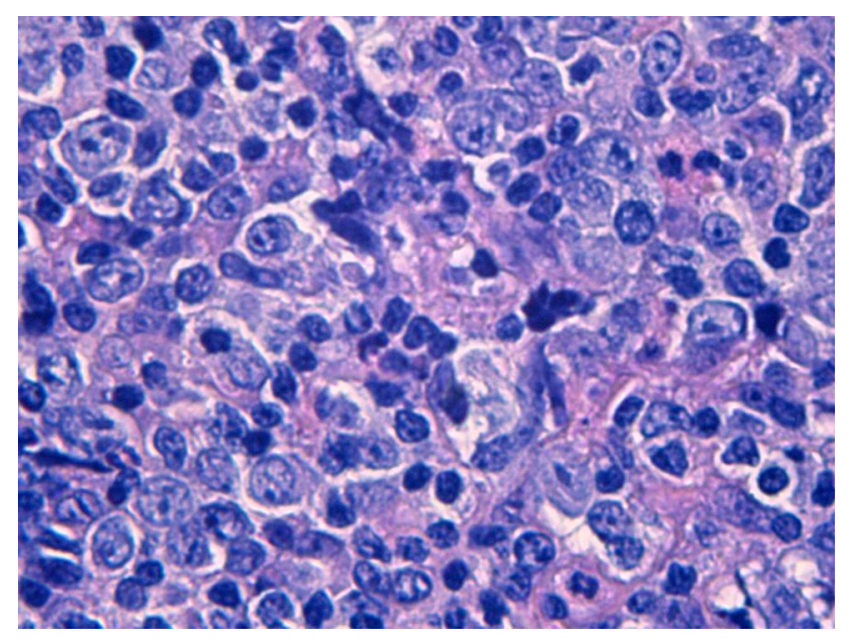

Figure I Pathological features: heteromorphic large lymphocyte proliferation, HE staining, magnification, $400 \times$. a diffuse large B-cell lymphoma, non-central cell tumor. PET/CT examination showed multiple hypermetabolic lymph nodes next to the external iliac vessels and bilateral inguinal regions (Figure 3), which were consistent with the changes in lymphoma infiltration changes. Epstein-Barr (EB) virus NA-IgG and EB virus VCA-IgG antibodies were positive, and EB virus (EBV) DNA quantification was $2.65 \times 10^{4}$ copies/mL (normal range, 0 to 5000 copies/ $\mathrm{mL})$. In-situ hybridization for Epstein-Barr virus-encoded RNA was scattered positive (Figure 4). A bone marrow aspiration biopsy showed normal tissues. Based on the Ann Arbor system for NHL staging, we diagnosed her a stage II primary urethral diffuse large B-cell lymphoma. According to the International Prognostic Index (IPI), the patient's IPI score was 1 and belonged to the lowintermediate-risk group.

Half a month after the surgery, oncologists reviewed the case and recommended an 8-cycles R-CHOP protocol (600 mg rituximab on day $1,600 \mathrm{mg}$ cyclophosphamide on days 1 and 2, $40 \mathrm{mg}$ doxorubicin on day 1, $2 \mathrm{mg}$ vincristine on day 1 , and $10 \mathrm{mg}$ dexamethasone on days 1 through 5 with 21-days cycles). After 2 cycles of treatment with standard chemotherapy, the EBV DNA quantification rechecked for six consecutive months were normal. After 4 cycles of chemotherapy, re-examination by PET-CT showed no signs of recurrence of the hypermetabolic tumors after chemotherapy for vulvar lymphoma, and signs of slightly larger lymph nodes along the external iliac vessels and inguinal regions, without significant metabolism increases (Figure 5). Adding methotrexate was prescribed during 5 th chemotherapy cycle to prevent central nervous system (CNS) relapses. Reexamination by PET-CT showed no obvious signs of tumor recurrence six months later after completing 8 chemotherapy courses (Figure 6). No recurrences or distant metastases have been found in the patient so far. The ratio of albumin to globulin has fluctuated between 1.5 and 1.7 and the neutrophil count has remained normal.

\section{Discussion}

DLBCL has its highest incidence after the age of 60 years ${ }^{8}$ with the median age at diagnosis being 70 years or older. ${ }^{9,10}$ The exact etiology of DLBCL is unknown. Masuda et al observed 6 cases of urethral lymphoma, and found that 3 of them had chronic urethral inflammation. ${ }^{11}$ Women were more prone to urethral inflammation than men due to their urethral anatomical structure of the urethra, and urethral lymphomas were more common in 

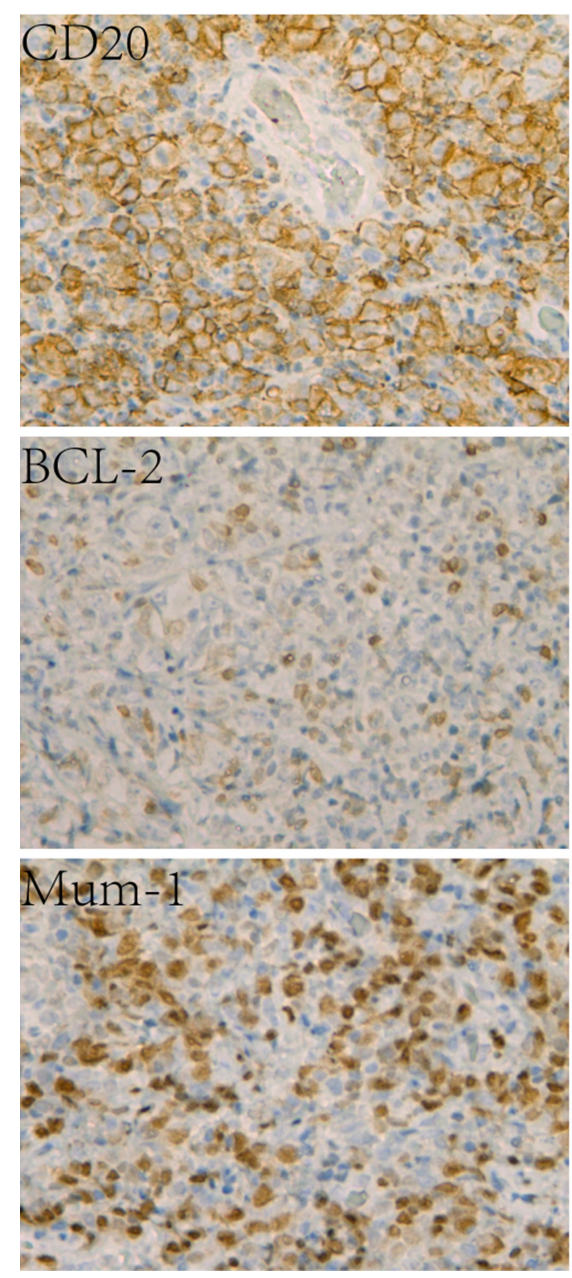
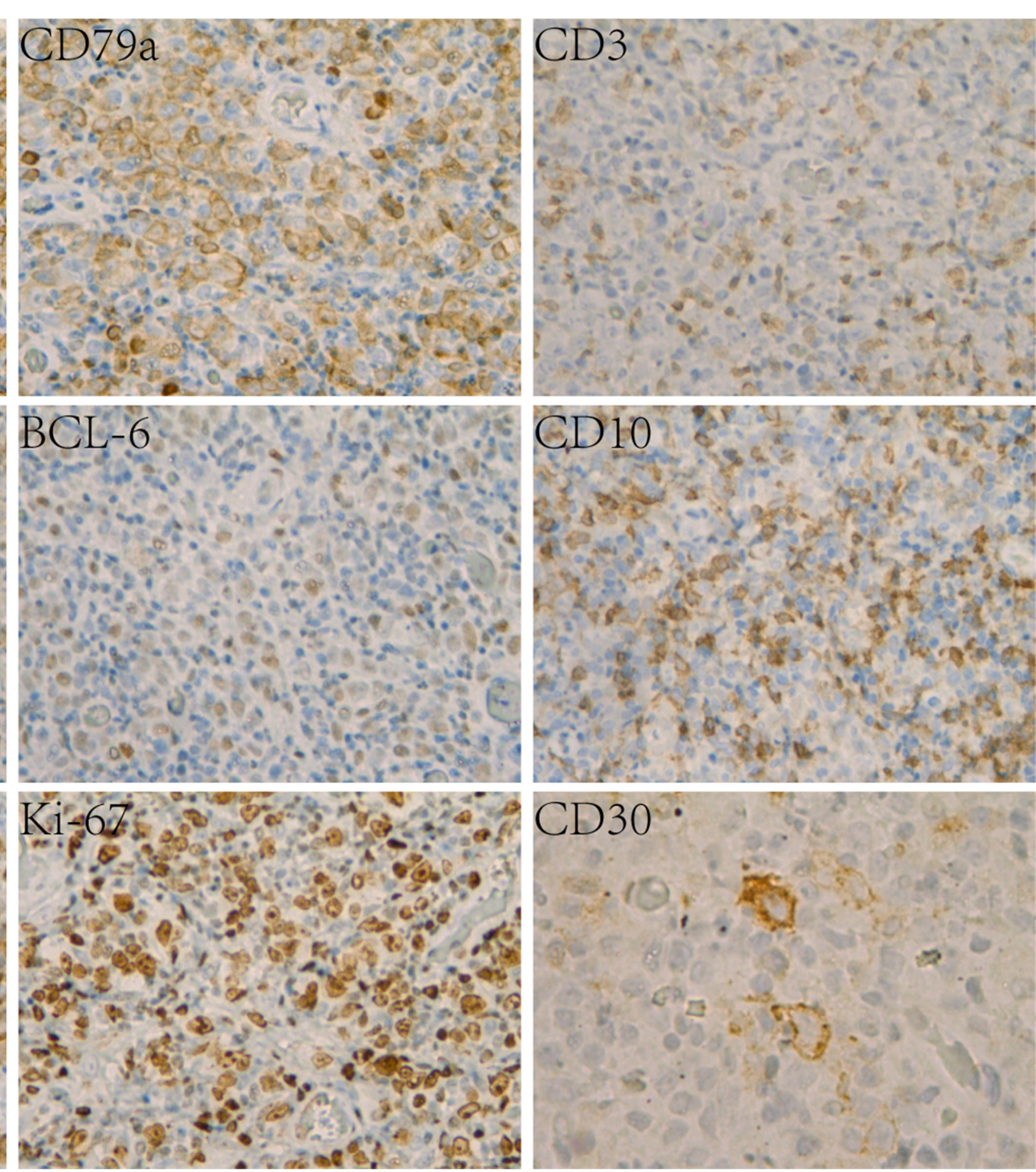
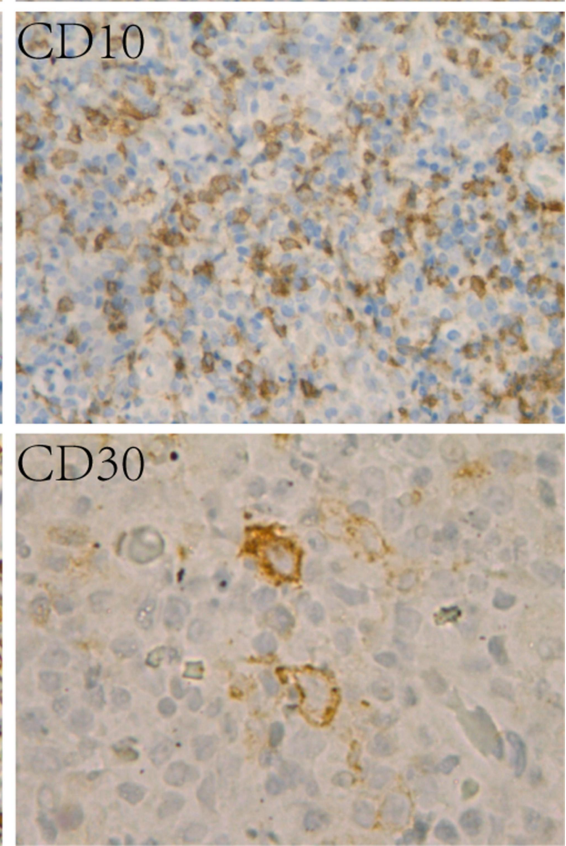

Figure 2 Immunohistochemical stains: CD20 (+++), CD79a (+++), CD3(-), BCL-2(-), BCL-6(+), CDI0(-), MUM-I(+), Ki-67(+>90\%) (HE staining, 200×), and CD30 scattered positive (HE staining, magnification, $400 \times$ ).

women. ${ }^{12}$ To date, only fifteen cases of primary diffuse large B-cell lymphoma of the urethra have been reported in the literature: The distribution age ranged from 30 to 90 years with a mean of 63 years (11 of them were women and 4 were men; Table 1). ${ }^{13-26}$ In our case, the urine culture of the patient was positive for Escherichia coli. Zeng et al detected EB virus gene in female urethral lymphoma lymphocytes by in situ hybridization. ${ }^{26}$ The EB virus NA-IgG and EB virus VCA-IgG antibodies were positive in our patient, and in-situ hybridization for Epstein-Barr virus-encoded RNA is scattered positive. Some patients with autoimmune disease (AIDs) have an increased risk of developing DLBCL. ${ }^{27} \mathrm{Kim}$ et al also found that patients with HIV had a high incidence of lymphoma. ${ }^{28}$ Lopez et al reported that a man with AIDS and had urethral DLBCL. ${ }^{14}$ AbdullGaffar et al reported a woman with an HIV-infection and a primary CD20negative DLBCL. ${ }^{29}$ Moreover, the MYD88 mutation and the CD79B mutations may be important factors in the occurrence of primary breast and primary female reproductive tract DLBCLs. ${ }^{30}$ In summary, the occurrence of DLBCL of the urethra may be related to chronic urethral inflammation, viral infection, autoimmune disease, gene mutation, or other factors.

Painless progressive lymphadenopathy or local mass is a common clinical manifestation of lymphomas, but the clinical manifestations of DLBCL at the urethral orifice are often atypical. The most common symptom is dysuria, but some patients present symptoms such as gross hematuria, frequent urination, and urgency. Physical examination reveals that most urethral DLBCLs are polypoid lesions or masses, and imaging examination results are non-specific, resulting in frequent clinical misdiagnoses as urethral polyps. Routine examinations cannot be distinguished from urethral polyps and urethral cancer, and the diagnosis is mainly based on the characteristics of tumor 


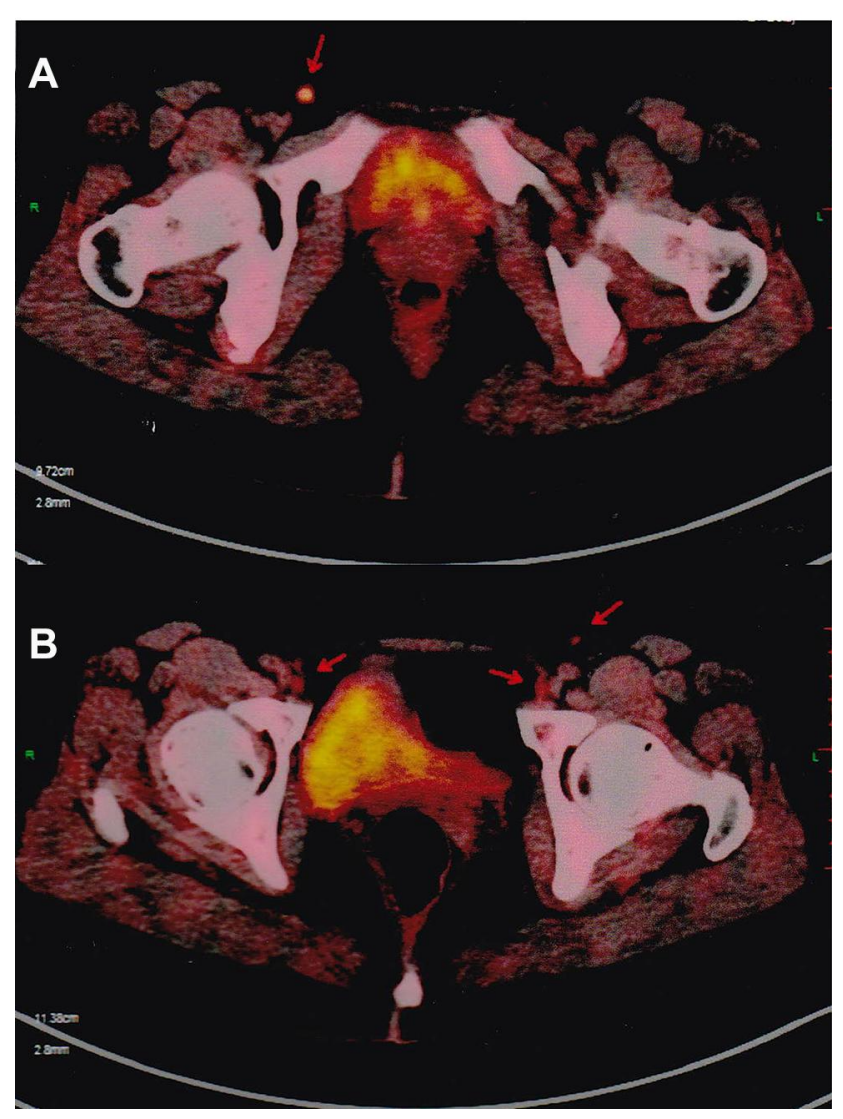

Figure $3 \mathrm{PET} / \mathrm{CT}$ scan results before chemotherapy: multiple hypermetabolic lymph nodes along bilateral inguinal regions $(\mathbf{A})$ and external iliac vessels $(\mathbf{B})$. The red arrow points to hypermetabolic lymph nodes.

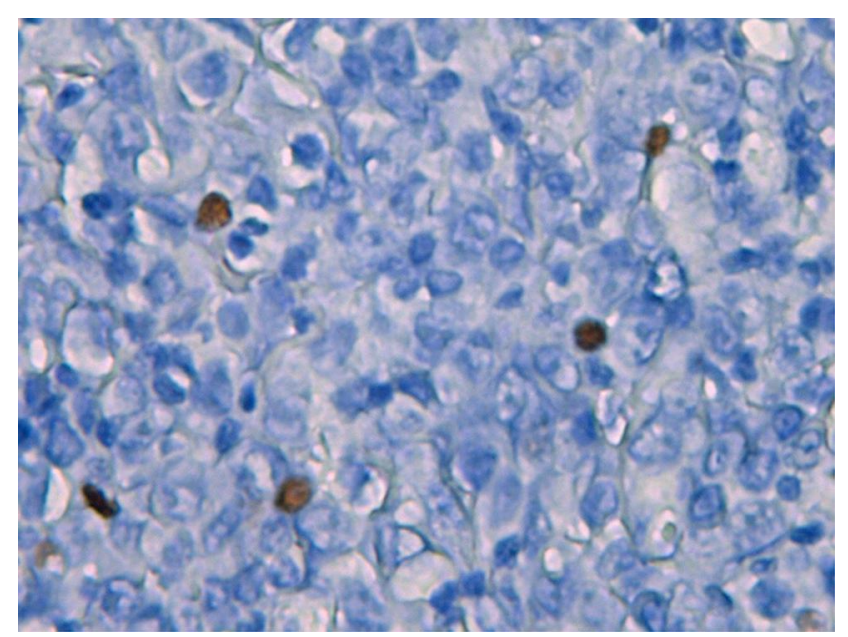

Figure 4 In-situ hybridization for Epstein-Barr virus-encoded RNA is scattered positive, HE staining, magnification, $400 \times$.

cells and immunohistochemical characteristics under the microscope. Typical immunological characteristics include positivity for CD20 and CD79a. In particular, CD20 is often strongly positive because it is a specific signal

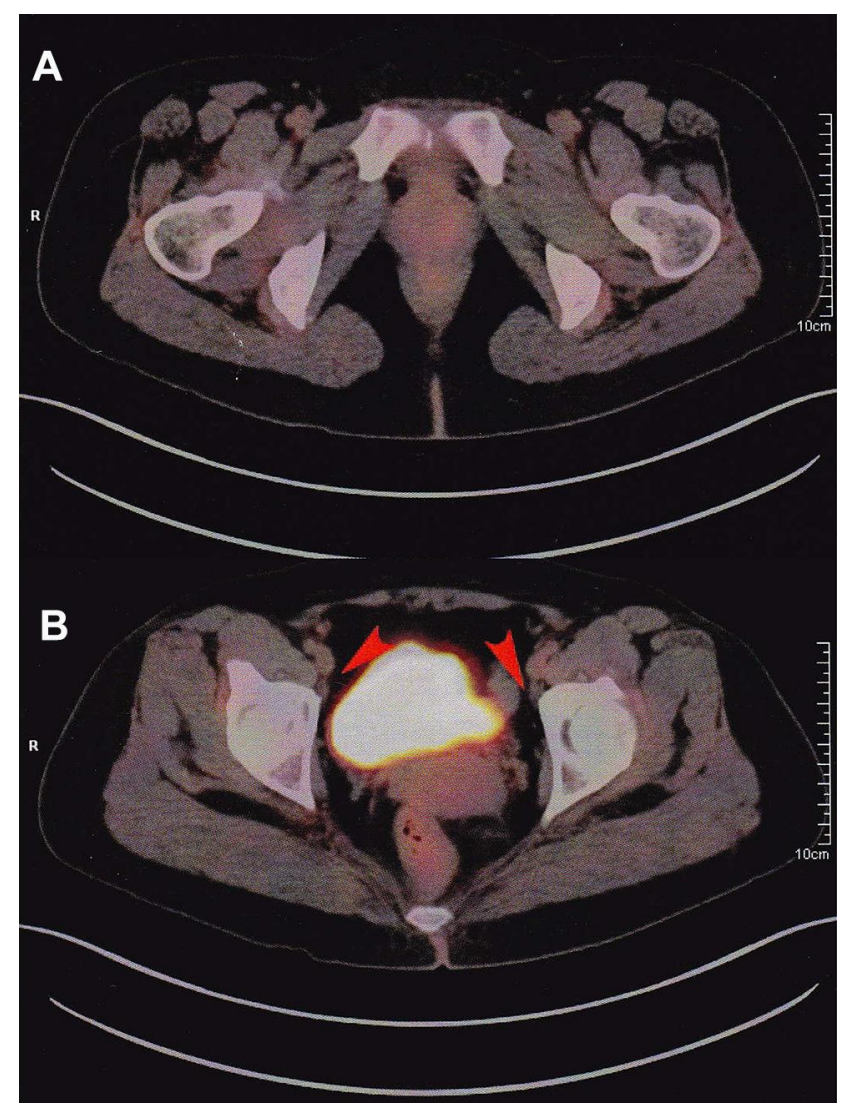

Figure 5 PET/CT scan results after the 4th chemotherapy: slightly larger lymph nodes lacking significant metabolic increases along the inguinal regions $(\mathbf{A})$ and the external iliac vessels (B). The red arrow points to slightly larger lymph nodes.

molecule on the surface of B cells, and it plays an important regulatory role in the proliferation and differentiation of B cells. Moreover, CD20 expression in B cells is associated with malignant tumors, and it is expressed in more than $95 \%$ of B-cell lymphomas. ${ }^{31}$

The differential diagnosis of urethral DLBCL includes urethral polyps and urethral cancer. In menopausal women, urethral polyps are the most common lesions in their urethral orifices. DLBCL in the urethral orifices is visually similar to a polyp. Microscopically, the urethral polyps present hematoma-like features. Inflammatory cells are often infiltrating the tissue, but their population is relatively complex, including neutrophils, lymphocytes, and plasma cells. In addition, the inflammatory cells are mature and small in size. However, lymphoma cells of the urethra, larger in size than mature lymphocytes, are often diffusely grown, and the cells are atypical and present frequent mitosis stages. The clinical manifestations of urethral cancer are generally local masses with frequent urination, hematuria, and urethral obstruction. However, urethral cancer is rare in the clinical practice 


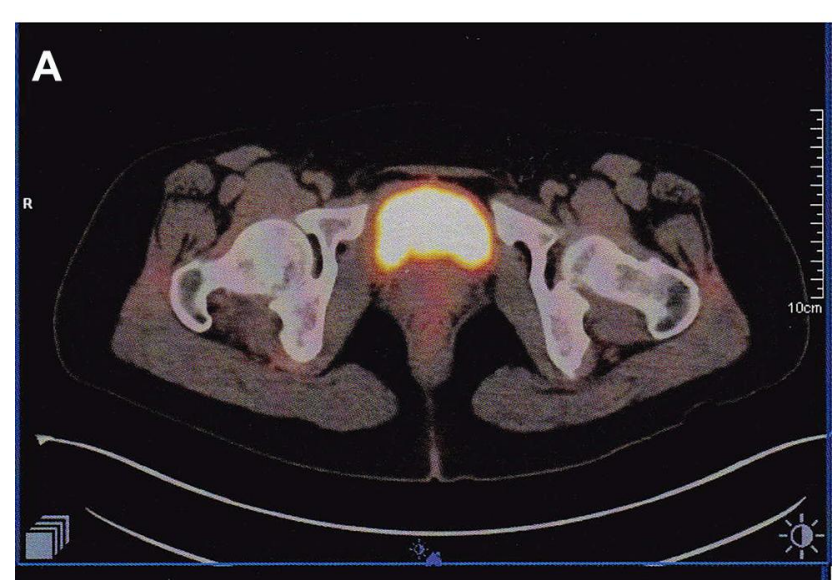

\section{B}

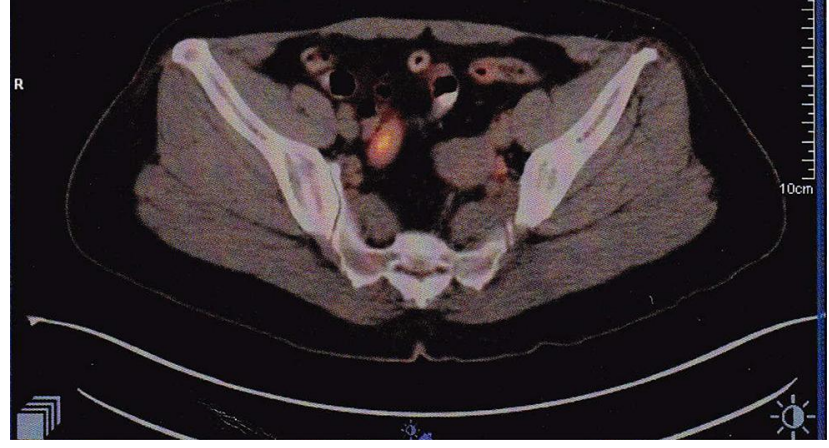

Figure $6 \mathrm{PET} / \mathrm{CT}$ scan results six months later after completing 8 chemotherapy courses: No signs of tumor recurrences along bilateral inguinal regions $(\mathbf{A})$ or external iliac vessels (B).

affecting more women than men (more commonly elderly individuals). Moreover, EBV-viral load is reported as significantly elevated and this may suggest a diagnosis of EBV+ DLBCL. The median age at diagnosis was 70 years in EBV+ DLBCL (NOS) patients and the study group exhibited a male predominance (65\% of patients). The majority of EBV + DLBCL (NOS) patients presented with advanced stage disease (stage III/IV), had B symptoms (fever, night sweats, weight loss) and elevated LDH. Seventy-five percent of patients had $\mathrm{CD} 30$ positive expression rate greater than $20 \%$, and most patients were negative for BCL- 6 and positive for BCL-2. ${ }^{32}$ However, this patient was a 52-year-old female with no obvious B symptoms and normal LDH. In addition, immunohistochemistry showed that BCL-2 expression was negative but BCL-6 expression was positive, and CD30 expression was scattered positive, and Ann Arbor staging was stage II. It is not clear that the cutoff for a positive expression of EBER in DLBCL patients. The positive rate used in previously published studies ranged from $10 \%$ to $50 \%{ }^{33}$ Castillo et al observed the response rate of EBVpositive DLBCL patients after chemotherapy and found that $92.31 \%$ of patients have an EBER-positive rate greater than $20 \%{ }^{34}$ Therefore, this patient cannot be diagnosed as $\mathrm{EBV}+\mathrm{DLBCL}$, and she just can be considered as diffuse large B-cell lymphoma with EBER scattered positive.

Treatment strategies should be stratified according to age, IPI, and feasibility of dose-intensified approaches. According to the European Society for Medical Oncology (ESMO) clinical practice guidelines for treatment of DLBCL, either R-CHOP $21 \times 6$ with radiotherapy to the sites of previous bulky disease or an intensified regimen R-ACVBP (rituximab, doxorubicin, vindesine, cyclophosphamide, bleomycin, and prednisolone) is recommended for young lowintermediate-risk patients (aa-IPI $=1$ ) or those with low risk IPI (aa-IPI $=0$ ) and bulky disease. ${ }^{35}$ Chinese guidelines for diagnosis and treatment of diffuse large B-cell lymphoma recommended that patients with aa-IPI $=1$ should consider R-CHOP $21 \times 8 .{ }^{36}$ Studies showed that elderly patients with DLBCL, who do not meet the criteria for the R-CHOP chemotherapy regimen, should receive treatment with ofatumumab combined with bendamustine that displays a total response rate of $90.5 \%{ }^{37}$ Asparaginase can inhibit DLBCL cell proliferation and induces DLBCL cell apoptosis, and it may be another treatment method. ${ }^{38}$

DLBCL is an invasive disease with a survival lower than 12 months without treatment. ${ }^{8}$ Two-thirds of patients with DLBCL were cured with standard immunochemotherapy, but a proportion of them did not respond to the initial treatment or may relapsed, ${ }^{39}$ and most relapses occurred within 1 to 2 years after diagnosis. ${ }^{2}$ Patients with DLBCL who are event-free at 2 years have an identical OS to that of the general population. ${ }^{35}$ Table 1 shows that although most patients have not been followed up for a long time, those whose tumors have not spread have a good prognosis after surgical resection and chemotherapy (one patient has had no disease recurrences after 48 months of follow-up ${ }^{24}$ ). In addition, one patient with disseminated disease also had a good prognosis after CHOP chemotherapy and had no disease recurrences after 24 months of follow-up. ${ }^{23}$ Studies have revealed that late disease, advanced age, and black race are predictors of poor DLBCL-specific survival, and that married individuals and women have a lower risk of DLBCL-specific death. ${ }^{40}$ The albumin to globulin ratio (AGR) is an important predictor of patients with diffuse large B-cell lymphoma, and a low AGR is an independent poor prognostic indicator of OS in newly diagnosed patients with DLBCL. ${ }^{39}$ The AGR of this patient was always normal. The life expectancy is the poorest among patients aged 50 
Table I Summary of Reported Cases of Primary Diffuse Large B-Cell Lymphoma of the Urethra

\begin{tabular}{|c|c|c|c|c|c|c|c|c|}
\hline Author & Year & Age & Sex & Clinical Presentation & Localization & Treatment & Outcome & $\begin{array}{l}\text { Follow } \\
\text { Up }\end{array}$ \\
\hline Chaitin $^{13}$ & 1984 & 77 & $\mathrm{~F}$ & $\begin{array}{l}\text { Vaginal mass, gross hematuria, fatigue } \\
\text { and weakness }\end{array}$ & Disseminated & $\begin{array}{l}\text { Chemo } \\
(C M+V P-16)\end{array}$ & NED & 9 months \\
\hline Lopez $^{14}$ & 1993 & 57 & M & $\begin{array}{l}\text { Intermittent hematuria and difficulty } \\
\text { voiding }\end{array}$ & Disseminated & Refused & $\begin{array}{l}\text { Died of pulmonary } \\
\text { embolism }\end{array}$ & 5 months \\
\hline Ohsawa ${ }^{15}$ & 1994 & 78 & $\mathrm{~F}$ & Polyuria and dysuria & Localized & $\begin{array}{l}\text { Exci+Chemo } \\
\text { (VEMP) }\end{array}$ & NM & NM \\
\hline Shimizu $^{16}$ & 1997 & 82 & $\mathrm{~F}$ & $\begin{array}{l}\text { Dysuria, sense of residual urine and } \\
\text { huge tumor }\end{array}$ & $\begin{array}{l}\text { Local } \\
\text { infiltration }\end{array}$ & $\begin{array}{l}\text { Radi+ Chemo } \\
(40 G y+V P-16)\end{array}$ & Dead & 5 months \\
\hline Chen ${ }^{17}$ & 2001 & 46 & $\mathrm{~F}$ & Urethral mass & Localized & NM & NM & NM \\
\hline Richter $^{18}$ & 2007 & 48 & M & $\begin{array}{l}\text { Voiding difficulty and urethral } \\
\text { bleeding }\end{array}$ & Localized & $\begin{array}{l}\text { Exci+Chemo } \\
\text { (R-CHOP) }\end{array}$ & NED & 3 months \\
\hline Muraoka ${ }^{19}$ & 2009 & 90 & $\mathrm{~F}$ & Dysuria and urethral mass & Localized & Exci+ Radi & NED & $\begin{array}{l}14 \\
\text { months }\end{array}$ \\
\hline Dong $^{20}$ & 2009 & 75 & $\mathrm{~F}$ & Intermittent gross hematuria, dysuria & Localized & $\begin{array}{l}\text { Exci+Chemo } \\
(\text { VP-16) }\end{array}$ & NED & 4 months \\
\hline $\mathrm{Xu}^{21}$ & 2010 & 44 & M & Frequent urination, dysuria & Localized & NM & NM & NM \\
\hline Zhang $^{22}$ & 2011 & 73 & $\mathrm{~F}$ & Dysuria & Localized & NM & NM & NM \\
\hline $\mathrm{Li}^{23}$ & 2012 & 70 & M & Dysuria, hematuria & Disseminated & $\begin{array}{l}\text { Chemo } \\
\text { (CHOP) }\end{array}$ & NED & $\begin{array}{l}24 \\
\text { months }\end{array}$ \\
\hline Zahrani $^{24}$ & 2012 & 30 & $\mathrm{~F}$ & Urethral mass & Localized & $\begin{array}{l}\text { Exci+Chemo } \\
\text { (R-CHOP) }\end{array}$ & NED & 48 months \\
\hline $\mathrm{Gao}^{25}$ & 2015 & 57 & $\mathrm{~F}$ & Urethral mass & Localized & $\begin{array}{l}\text { Exci+Chemo } \\
\text { (R-CHOP) }\end{array}$ & NED & 5 months \\
\hline Zeng $^{26}$ & 2015 & 55 & $\mathrm{~F}$ & Urgent urination, painful urination & Localized & $\begin{array}{l}\text { Exci+Chemo } \\
\text { (R-CEOP) }\end{array}$ & NED & $\begin{array}{l}21 \\
\text { months }\end{array}$ \\
\hline Zeng & 2020 & 52 & $\mathrm{~F}$ & $\begin{array}{l}\text { Urinary frequency, urgency, and } \\
\text { dysuria }\end{array}$ & Localized & $\begin{array}{l}\text { Exci+Chemo } \\
\text { (R-CHOP) }\end{array}$ & NED & \\
\hline
\end{tabular}

Abbreviations: Exci, excision; Chemo, chemotherapy; Radi, radiotherapy; NED, no evidence of disease; NM, not mentioned; CM, phosphamide, methotrexate; VEMP, cyclophosphamide, vincristine, 6-mercaptopurine and prednisone; VP-16, etoposide; R-CHOP/CEOP, rituximab, cyclophosphamide, doxorubicin/epirubicin, vincristine, and prednisolone/dexamethasone.

to 60 years with age-adjusted International Prognostic Index (aaIPI) $>29$. Moreover, studies have suggested that PRDX6 may be a target to overcome drug resistance. ${ }^{41}$ Autologous stem cell transplantation is the only known cure for disease relapses. ${ }^{10}$

In conclusion, our case report aims to raise awareness of this rare disease, and primary urethral DLBCL rarely occurs. Early diagnosis and standard treatment may improve the patient survival. Although the course of disease in our patient had lasted 1 year and the PET/CT scan had shown multiple hypermetabolic lymph nodes along the external iliac vessels and bilateral inguinal regions, our patient has experienced no recurrences or distant metastasis after surgical resection combined with R-CHOP chemotherapy.

\section{Ethics Approval and Consent to Patient}

This study has been exempted from requiring ethical approval by The Ethical Committee of the First Affiliated Hospital of Guangzhou University of Traditional Chinese Medicine (ZYYEC-ERK [2020] 053). We have solicited the patient's agreement before 
writing this case report. We confirm that written informed consent has been provided by the patient to have the case details and images published.

\section{Disclosure}

The authors report no conflicts of interest in this work.

\section{References}

1. Vannata B, Conconi A, Winkler J, et al. Late relapse in patients with diffuse large B-cell lymphoma: impact of rituximab on their incidence and outcome. $B r \quad J$ Haematol. 2019;187(4):478-487. doi:10.1111/bjh.16106

2. Emanuel AJ, Presnell SE. Acute kidney injury and cardiac arrhythmia as the presenting features of widespread diffuse large B-cell lymphoma. Autops Case Rep. 2019;9(3):e2019114. doi:10.4322/ acr.2019.114

3. Vapnek JM, Turzan CW. Primary malignant lymphoma of the female urethra: report of a case and review of the literature. J Urol. 1992;147 (3):701. doi:10.1016/S0022-5347(17)37358-5

4. Zaidi A, Gupta P, Saha PK, et al. Primary ovarian diffuse large B cell lymphoma: report of a rare case in a young female. J Adolesc Young Adult Oncol. 2019;8(6):702-706. doi:10.1089/jayao.2019.0048

5. Siegel R, Naishadham D, Jemal A. Cancer statistics, 2012. CA Cancer J Clin. 2012;62(1):10-29. doi:10.3322/caac.20138

6. Hong L, Lijuan Z, Xuemei Z, et al. The long-term efficacy of rituximab and clinical significance of interim evaluation with PET/ $\mathrm{CT}$ in patients with different forms of non-Hodgkin lymphoma. Jiangsu Med J. 2017;43(02):88-93.

7. Li S, Young KH, Medeiros LJ. Diffuse large B-cell lymphoma. Pathology. 2018;50(1):74-87. doi:10.1016/j.pathol.2017.09.006

8. Flowers CR, Sinha R, Vose JM. Improving outcomes for patients with diffuse large B-cell lymphoma. CA Cancer J Clin. 2010;60 (6):393-408.

9. Ekberg S, Jerkeman M, Andersson PO, et al. Long-term survival and loss in expectancy of life in a population-based cohort of 7114 patients with diffuse large B-cell lymphoma. Am $J$ Hematol. 2018;93(8):1020-1028. doi:10.1002/ajh.25147

10. Caglayan C, Goldstein JS, Ayer T, et al. A population-based multistate model for diffuse large B-cell lymphoma-specific mortality in older patients. Cancer. 2019;125(11):1837-1847. doi:10.1002/ cncr.31981

11. Masuda A, Tsujii T, Kojima M, et al. Primary mucosa-associated lymphoid tissue (MALT) lymphoma arising from the male urethra. A case report and review of the literature. Pathol Res Pract. 2002;198(8):571-575. doi:10.1078/0344-0338-00304

12. Rajan N, Allman D, Scaglia B, et al. NonHodgkin's lymphoma of the male urethra. J Urol. 1995;153(6):1916-1917. doi:10.1016/S00225347(01)67353-1

13. Chaitin BA, Manning JT, Nelson GO. Hematologic tumors with initial clinical manifestations in the lower urinary tract. Urology. 1984;23(1):35-42. doi:10.1016/0090-4295(84)90173-0

14. Lopez AE, Latiff GA, Ciancio G, et al. Lymphoma of urethra in patient with acquired immune deficiency syndrome. Urology. 1993;42(5):596-598. doi:10.1016/0090-4295(93)90287-K

15. Ohsawa M, Mishima K, Suzuki A, et al. Malignant lymphoma of the urethra: report of a case with detection of Epstein-Barr virus genome in the tumour cells. Histopathology. 1994;24(6):525-529. doi:10.1111/j.1365-2559.1994.tb00570.x

16. Shimizu Y, Ogawa O, Terachi T. A case of primary urethral lymphoma presenting as a huge mass surrounding the female urethra Hinyokika Kiyo. 1997;43(3):229-232.

17. Chen J, Wen X, Qian P, et al. A case of non-Hodgkin lymphoma of urethra. J Clin Urol. 2001;26(7):545.
18. Richter LA, Hegde P, Taylor JA. Primary Non-Hodgkin's B-cell lymphoma of the male urethra presenting as Stricture disease. Urology. 2007;70(5):1008-1011.

19. Muraoka K, Hunahashi M, Nagashima M, et al. A patient with a primary malignant lymphoma surrounding the female urethra. Hinyokika Kiyo. 2009;55(6):357-360.

20. Dong Q, Jia M, Jiang M. Non-Hodgkin lymphoma of female urethra: one case report. CHINA MOD MED. 2009;16(22):134-135.

21. $\mathrm{Xu} \mathrm{W}, \mathrm{Li} \mathrm{X}, \mathrm{Li} \mathrm{T}$, et al. A case of primary diffuse large B-cell lymphoma of anterior urethra. CHIN J DIAGN PATHOL. 2010;17 (5):396.

22. Zhang J, Chen Y, Shang D, et al. A case of non-Hodgkin lymphoma of female urethra. J Clin Urol. 2011;26(7):545.

23. Li F, Yu G, Ma W, et al. A case of non-Hodgkin's lymphoma invading the urethra. Chin J Surg. 2012;50(6):528.

24. Al Zahrani A, Abdelsalam M, Al Fiaar A, et al. Diffuse large B-cell lymphoma transformed from mucosa-associated lymphoid tissue lymphoma arising in a female urethra treated with rituximab for the first time. Case Rep Oncol. 2012;5(2):238-245. doi:10.1159/000333357

25. Gao W, Xu P, Han J, et al. Primary diffuse large B-cell lymphoma of the urethra: report of one case and review of the literature. $J$ Clin Urol. 2015;30(12):1077-1079.

26. Zeng Y, Zhu X, Zhang S, et al. Analysis of clinicopathological features of urethral lymphoma (Report of one case and literature review). J Clin Urol. 2015;30(04):299-301.

27. Morth C, Valachis A, Abu SA, et al. Autoimmune disease in patients with diffuse large B-cell lymphoma: occurrence and impact on outcome. Acta Oncol. 2019;58(8):1170-1177. doi:10.1080/0284186X.2019.1619936

28. Kim MS, Park JH, Kim JY, et al. Upper gastrointestinal bleeding caused by direct invasion of diffuse large B-cell lymphoma into the stomach in a patient with HIV infection: a case report. Medicine (Baltimore). 2019;98(28):e16363. doi:10.1097/MD.0000000000016363

29. Abdullgaffar B, Seliem RM. De Novo Unclassifiable CD20-negative diffuse large B-cell lymphoma: a diagnostic and therapeutic challenge. Int J Surg Pathol. 2018;26(3):266-270. doi:10.1177/ 1066896917735170

30. Cao XX, Li J, Cai H, et al. Patients with primary breast and primary female genital tract diffuse large B cell lymphoma have a high frequency of MYD88 and CD79B mutations. Ann Hematol. 2017;96(11):1867-1871. doi:10.1007/s00277-017-3094-7

31. Sun R, Zhu Y, Feng HL, et al. Effector mechanisms of Anti-CD20 monoclonal antibodies in killing B-cell lymphoma. Prog Mod Biomed. 2016;16(05):950-955.

32. Witte HM, Merz H, Biersack H, et al. Impact of treatment variability and clinicopathological characteristics on survival in patients with Epstein-Barr-Virus positive diffuse large $\mathrm{B}$ cell lymphoma. $\mathrm{Br}$ J Haematol. 2020;189(2):257-268. doi:10.1111/bjh.16342

33. Beltran BE, Castro D, Paredes S, et al. EBV-positive diffuse large Bcell lymphoma, not otherwise specified: 2020 update on diagnosis, risk-stratification and management. Am J Hematol. 2020.

34. Castillo JJ, Beltran BE, Miranda RN, et al. EBV-positive diffuse large B-cell lymphoma, not otherwise specified: 2018 update on diagnosis, risk-stratification and management. Am J Hematol. 2018;93 (7):953-962. doi:10.1002/ajh.25112

35. Tilly H, Gomes DSM, Vitolo U, et al. Diffuse large B-cell lymphoma (DLBCL): ESMO Clinical Practice Guidelines for diagnosis, treatment and follow-up. Ann Oncol. 2015;26(Suppl 5):v116-v125. doi:10.1093/annonc/mdv304

36. Hematology C M A C. Lymphoma C A A C. Chinese guidelines for diagnosis and treatment of diffuse large B cell lymphoma (2013). Zhonghua Xue Ye Xue Za Zhi. 2013;34(9):816-819.

37. Flinn IW, Erter J, Daniel DB, et al. Phase II study of bendamustine and ofatumumab in elderly patients with newly diagnosed diffuse large B-cell lymphoma who are poor candidates for R-CHOP chemotherapy. Oncologist. 2019;24(8):1035-1623. doi:10.1634/ theoncologist.2019-0286 
38. Gao X, Jiao J, Liu M, et al. Effect of asparaginase on diffuse large B-cell lymphoma cell apoptosis and its related mechanism. $J$ Exp Hematol. 2019;27(5):1482-1489.

39. Yue W, Liu B, Gao L, et al. The pretreatment albumin to globulin ratio as a significant predictor in patients with diffuse large B cell lymphoma. Clin Chim Acta. 2018;485:316-322. doi:10.1016/j. cca.2018.07.015

40. Howlader N, Mariotto AB, Besson C, et al. Cancer-specific mortality, cure fraction, and noncancer causes of death among diffuse large B-cell lymphoma patients in the immunochemotherapy era. Cancer. 2017;123(17):3326-3334. doi:10.1002/cncr.30739
41. Fang Z, Liu T, Liu X, et al. PRDX6 promotes proliferation and induces chemo-resistance via peroxidase activity in Toledo diffuse large B-cell lymphoma cells. Transl Cancer Res. 2019;8 (5):1772-1781. doi: $10.21037 /$ tcr.2019.08.36

\section{Publish your work in this journal}

OncoTargets and Therapy is an international, peer-reviewed, open access journal focusing on the pathological basis of all cancers, potential targets for therapy and treatment protocols employed to improve the management of cancer patients. The journal also focuses on the impact of management programs and new therapeutic

Submit your manuscript here: https://www.dovepress.com/oncotargets-and-therapy-journal agents and protocols on patient perspectives such as quality of life, adherence and satisfaction. The manuscript management system is completely online and includes a very quick and fair peer-review system, which is all easy to use. Visit http://www.dovepress.com/ testimonials.php to read real quotes from published authors. 